\title{
Do Marine Scientists Have A SCIENTIFIC VIEW OF THE EARTH?
}

\author{
By Gunther Krause and Matthias Tomczak
}

$\mathbf{O}$ NE OF THE GREAT challenges of marine sciences has always been to integrate the information collected over many decades by the oceanographic community into a global picture of life and water movement in the world ocean. The advent of satellites has assisted us greatly: we are now presented with quasi-synoptic global views of our planet on a daily basis. Developments in computer technology were essential to this change, since without them today's satellites could neither fly nor transmit oceanographic information.

A parallel development occurred with the advent of global ocean circulation and coupled atmosphere/ocean models. These models offer us a synthetic but truly synoptic view of the World Ocean. enabling us to fill in circulation details in regions of low tield-data density and extrapolating into times not covered by observations. Again. developments in computer technology made this possible.

Arithmetic operations on large matrices the backbone of general circulation models) and rapid processing of large data streams (the basis of satellite data transmission/ can be considered classical applications of electronic computers. A third. equally important area of computer application that emerged gradually from experience is data visualization. It has become clear that satellite data. results from ocean models. or climatological information extracted from global data base can no longer be displayed. studied. or understood $"$ ithout computer-based image processing.

The combination of these technological developments has opened many new avenues for marine research. Operational prediction of El Niño. analyis of eddy intensity in the Circumpolar Current. the modeling of possible climate trends are rome examples of what has become pousible tonday. This paper diccuses an interesting side-ef-

G. Kratwe. Altred-Wegener-In-ntut für Polar- und Necra-

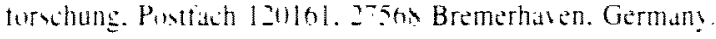
M. Tomezak. Flinders Institute for Marine and Atmospheric Sciences. Flinders University. GPO Box 2100. Adelaide SA simol. Auntralia. fect of computer-assisted image displays. the emergence of what could be called the "squaregridded earth".

The square-gridded earth occurs in many forms. The example shown in Figure 1 is particularly instructive since the caption that accompanied it in the original paper specifically mentioned the use of a particular image processing software for the preparation of the figure. Image processing software requires uniform data distribution. On the square-gridded earth this is achieved by supplying the data on a grid of constant latitude and longitude and by plotting latitude and longitude on linear scales. Note that latitude and longitude are both length measurements against a reference location and therefore have the same unit imeter). However. software packages allow for the free choice of the lengths of $x$ - and $y$-axes. For layout or aesthetic reasons we therefore find many aspect ratios of square-gridded representation of global data fields. As they come together with the contours of the continents we tend to convider such graphies as "maps".

Apparently. oceanographer treat horizontal data fields in a similar way as vertical distributions. In the latter case there are good reasons to display the same unit with different caling factors. When displaying hydrographic ections it is uval and necewary to expand the vertical scale by a factor of 100 or more relative to the horizontal wale. This is juvtified by the fact that the ocean is a thin film of atratified fluid and that vertical exaggeration of caales is the only way to display its structure. Similarly compelling reason do not exist when it comes to the presentation of data on a horizontal surface.

The question of the correct anpect ration is. hom ever. trivial when we consider the main problem raised by the proliferation of the -quare-gridded earth concept. We hate knoun for wome time that the Earth iv wery close tol a phere: anyone who still needs convincing ean now see compelling proof in space photographs returned from satellite missions. What many of us do not seem to realize ne of the great

challenges of marine

sciences has always

been to integrate the

information collected

over many decades

by the oceanographic

community into a

global picture of life

and water movement

in the world ocean. 


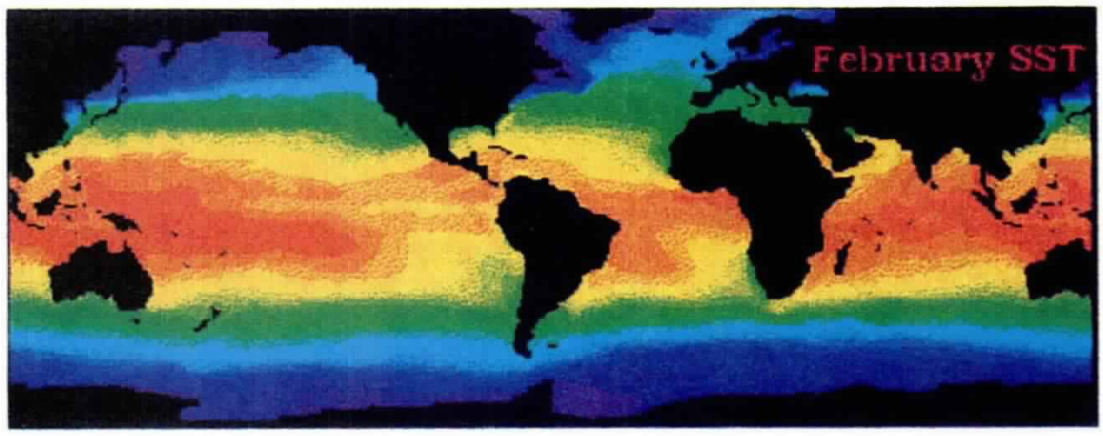

Fig. 1: One of the realizations of the "square-gridded earth" as seen in our TOS journal: Climatological sea surface temperature in February. Though no latitude and longitude axes are shown, it is clear that both are plotted on linear scales. From Sharp and McLain (1993). Cartographers know the square-gridded earth as Platt's map.

is that transformation of data fields from a spherical surface to a plane is more than a simple exercise in graphing, such as the drawing of isopycnals in a temperature-salinity diagram or the contouring of surface temperature along a repeat XBT section as a function of time and distance along the track. It is a scientific exercise in itself in which principles of geodesy are applied.

There are many ways to project a spherical surface into a plane. Some projections are better than others, some are more useful for a given application than others. In this note we want to point out the importance of the correct choice of projection

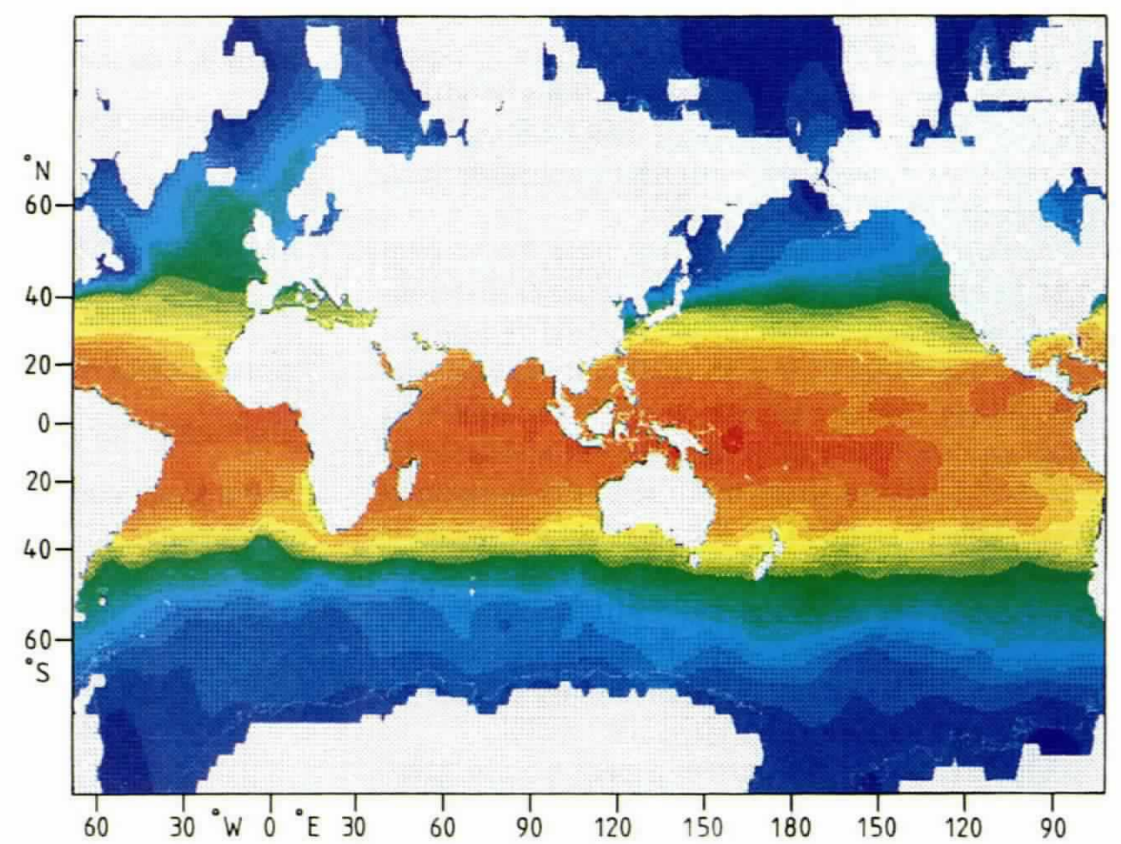

Fig. 2: The information of Figure 1 shown in Mercator projection from $78.5^{\circ} \mathrm{S}$ to $80^{\circ} \mathrm{N}$. (The data are taken from Levitus, 1982, while the data for Figure 1 are based on an atlas of Bauer and Robinson as given by Sharp and McLain, 1993. The color coding is slightly different from the palette used by Sharp and McLain.)

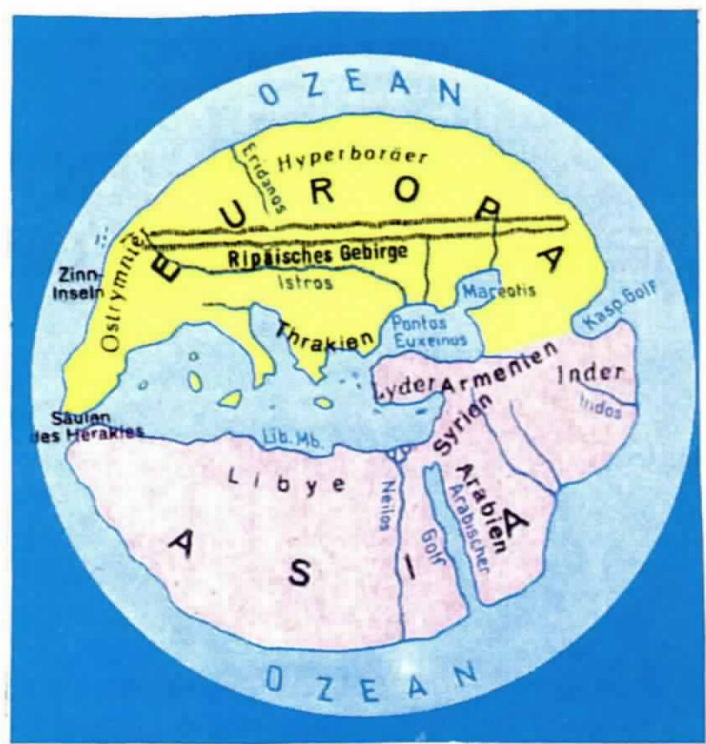

Fig. 3: The map of Greek philosopher Hekataios, devised about 500 B.C., showing Europe, Asia, and Libya (now Africa), with Hekataios' birthplace in its center.

for different applications. We review the effect different projections have on our view of the world. We conclude with a discussion of the most appropriate projections for oceanographic applications.

A fundamental property of all projections is that they are based on conversion algorithms which establish unique relationships between positions on the sphere and positions on the plane, conserving at least one important property in the process. Which property is considered important varies from application to application, but the following properties generally are recognized as im-

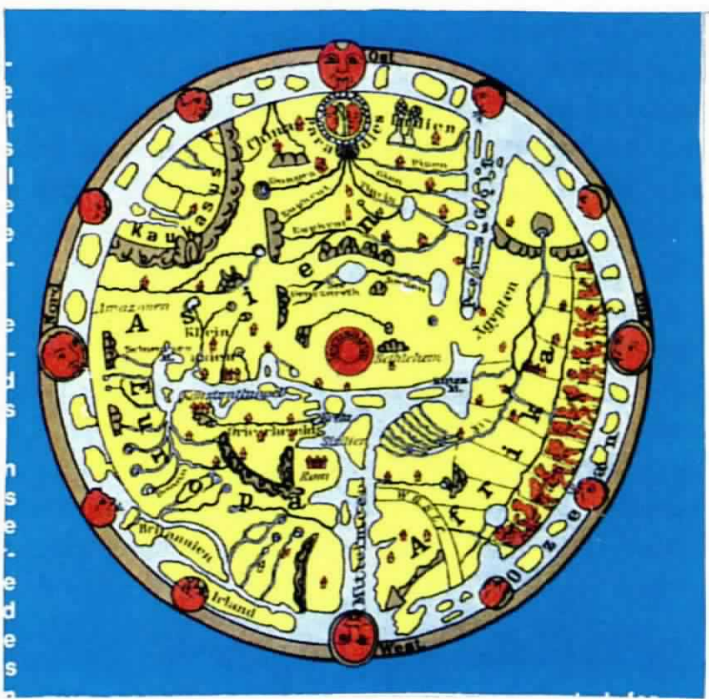

Fig. 4: The London Psalter map from the 13th century showing Bethlehem in the center. 
portant: 1) fidelity of area, 2) fidelity of angle, 3) choice of any pair of meridians as map boundaries without redrawing, and 4) east always to the right, north always up (i.e., a rectangular coordinate system). The first two are fundamental for a realistic depiction of the Earth, while the last two are important if the intention is to produce a map useful for scientific data presentation and position plotting.

Obviously some of the properties are mutually exclusive, so every projection can only do justice to some. Fidelity of distance would be considered paramount in the preparation of a road atlas, which (assuming uniform road conditions) would allow estimation of travel times at a glance but could not have fidelity of area or angle. Unfortunately, no projection can conserve distance over the entire map surface, so every road atlas is only an approximation. Fidelity of angle is of primary concern for navigation to allow a ship or aircraft officer to read the compass angle directly from the position grid on the map. This is the scientific basis for the Mercator projection of 1569 (Figure 2 ), a great scientific achievement and an indispensable tool for oceanographic cruise planning. The Mercator map does not have fidelity of area, but it includes the convenience of a rectangular coordinate system.

Fidelity of area is important in many oceanographic applications, because the coupling between the ocean and the atmosphere occurs at the sea surface, and most exchange processes are proportional to the area of contact. The Mercator projection would be an inappropriate tool for this field of research, because it shows the tropics and subtropics, between $30^{\circ} \mathrm{S}$ and $30^{\circ} \mathrm{N}$, as $43 \%$ of the map area between $60^{\circ} \mathrm{S}$ and $60^{\circ} \mathrm{N}$, and as $28 \%$ of the map area between $75^{\circ} \mathrm{S}$ and $75^{\circ} \mathrm{N}$, whereas in reality they cover, of course, half the surface of the earth. The Mercator map therefore invites us to underestimate the role of the tropics in air/sea interaction. The square-gridded earth suffers from the same problem; it shows the region between $30^{\circ} \mathrm{S}$ and $30^{\circ} \mathrm{N}$ as $33 \%$ of the map area. In contrast to the Mercator projection, it does not conserve a single fundamental property of projections and in fact is not a projection at all, since it is not derived from geodetic principles. It is a visualization concept, i.e., it may have artistic merit but is of little scientific value and should not have a place in the scientific literature.

Before we go on to a discussion of appropriate projections for world ocean applications it may be useful to dwell a bit on the interaction between map projections and our view of the Earth. To begin with, a map is a reflection of knowledge about the surface of the earth at the time of the map's design. Once established, it takes on a life of its own and begins to influence people's perception of the world. Take for example the map of Greek philosopher Hekataios (Fig. 3) that he

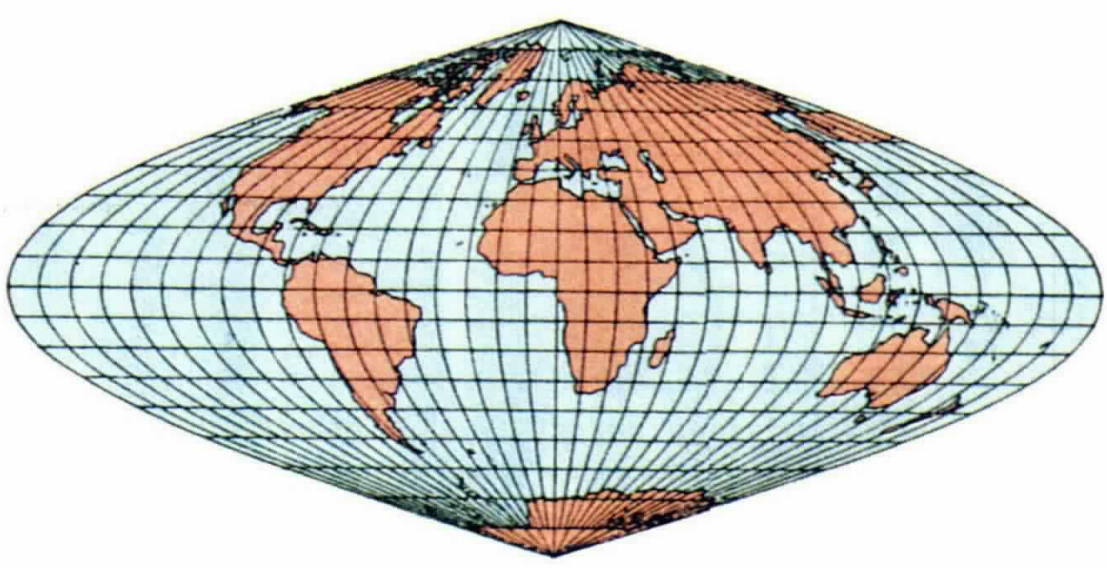

Fig. 5: The continents of the earth shown in Sanson's projection of 1650.

designed about 500 B.C.; it summarized all existing knowledge about the living space of his civilization. Every ancient traveller reported that his voyage came to an end at the shore of a big unsurmountable sea, information that was corroborated by the reports of seafarers who testified that the sea was endless. So the natural model emerged that the earth appeared as a disk surrounded by water. This admirable first model of the world of the Mediterranean civilizations survived for almost 2,000 years, even though a fellow Greek mathematician and geographer, Erasthosthenes, showed as early as 222 B.C. that the earth is a sphere.

One of the reasons for the longevity of the Hekataios map is that the church in Europe adopted the disc model to illustrate Heaven above, Hell below. Paradise in the east, and Jerusalem as the center of the world. An example of the charts produced during these years is the famous "London Psalter map" (Fig. 4), which dates from the thirteenth century. The wide-spread acceptance of the disc model represented a major defeat for scientific exploration and interpretation.

The change came with the capture of Constantinople, where the concept of the spherical earth

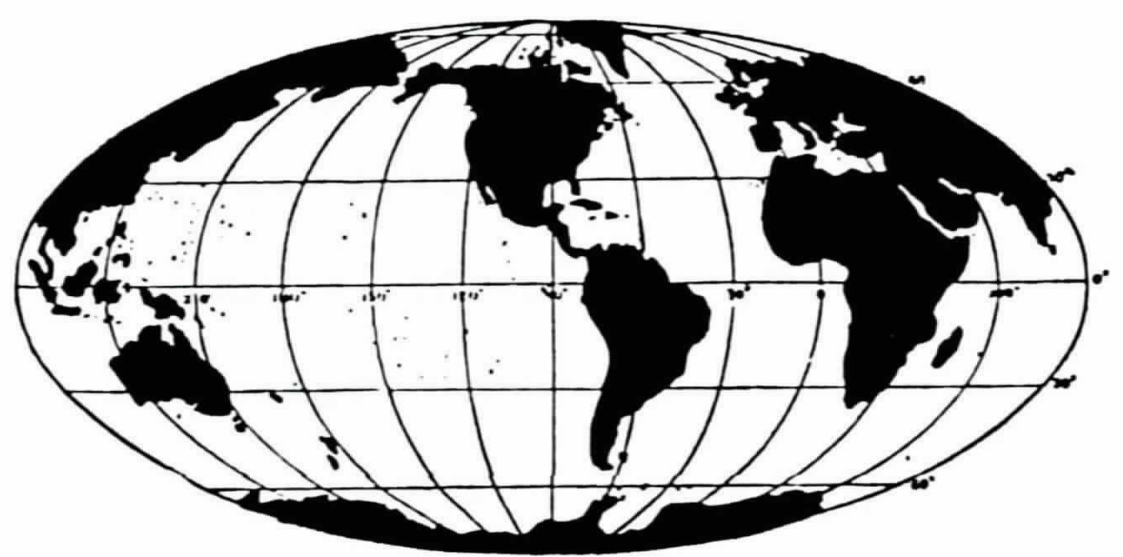

Fig. 6: An example of the Mollweide projection. reflection of knowledge about the surface of the earth at the time of the map's design. 


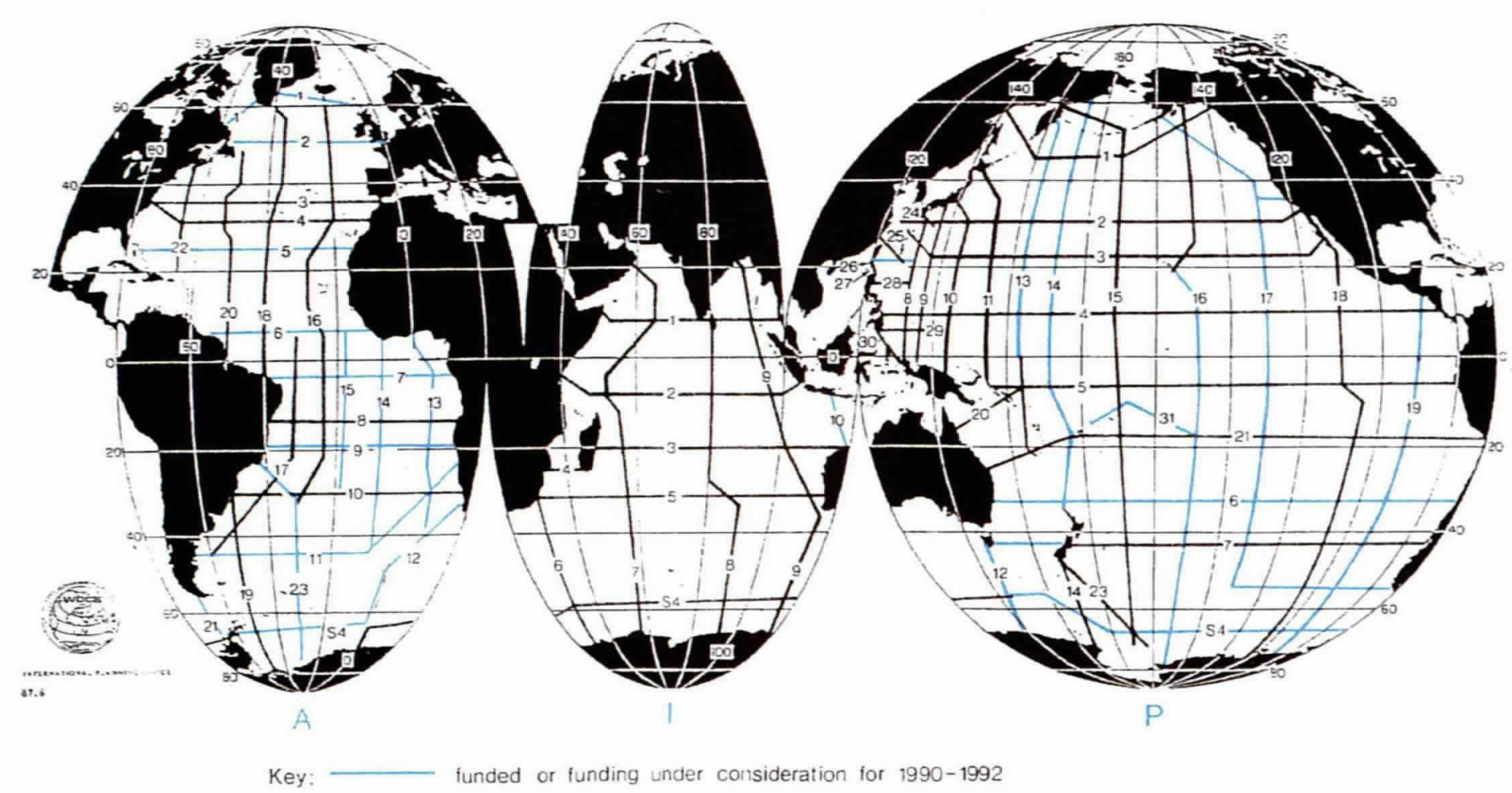

Fig. 7: The WOCE hydrographic network as produced by the International WOCE Office (WOCE Newsletter number 9, February 1990).

had been maintained, by the Turks in 1453. Scholars who fled the city carried Ptolemy's teachings into Europe: Ptolemy shows the world on a halfsphere, which depicts only $8 \%$ of the true size of the earth's surface. This was the map Columbus saw before he went on his voyage of discovery. Without doubt, he was greatly assisted in making his historic decision by the large underestimation of distances on this map (Peters, 1983).

The success of Mercator's projection in making the task of navigation officers easy and straightforward established the Mercator map as a standard and gave it widespread use. Even today it can still be seen in school atlases and on television screens. The effect of this map on our perception of the world should not be underestimated. Ask any high school student which is larger, the former Soviet Union or Africa-chances are that the answer is

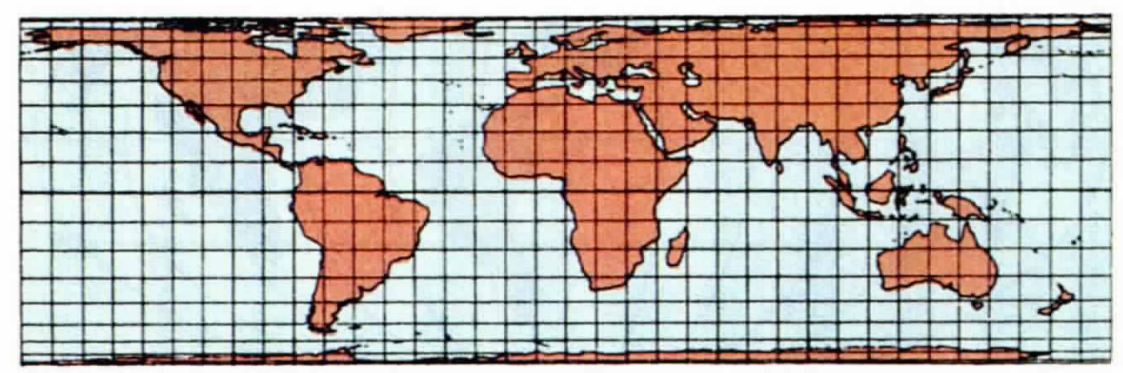

Fig. 8: The Lambert projection of 1772, the first projection that combined fidelity of area with a rectangular latitudellongitude grid. the Soviet Union. Go into more detail and compare Egypt with France; many people (including scientists) would assert that France is about the size of Egypt when in reality Egypt is, of course, nearly twice as large as France, and the former Soviet Union is only three-quarters the size of Africa. As a final test, ask which is larger, Greenland or Arabia-Greenland is about two-thirds of Arabia's size.

A map with such distortions makes comparative evaluation of air/sea interaction processes in different parts of the world ocean a difficult task. How much of the Pacific Ocean, for example, is taken up by the "warm pool" in the western equatorial region? Does the area of the equatorial current system really exceed that of the subpolar gyres? How much of the ocean surface is affected by El Niño anomalies? Try and find the answers from a Mercator map or from a map of the squaregridded earth; you will be convinced of the value of area-conserving projections.

Projections that maintain fidelity of area have been known for quite some time. The Sanson projection of 1650 (Fig. 5) was based on sketches originally developed by Mercator. Other projections such as the Mollweide (Fig. 6), the Aithoff, or the Hammer display a more rounded shape and are therefore often preferred. Although when it comes to area comparisons, these projections are superior to the square-gridded earth and the Mercator projection, there is no simple way to use them for different parts of the earth's surface. A Mollweide projection of the Indian Ocean, for ex- 
ample, would require a complete redrawing of all coastlines (see Fig. 6). This is probably the reason why the International WOCE Office seems to favor a projection (Fig. 7) in which the earth appears as a peeled orange so that each ocean is seen in one piece.

Another major disadvantage that the Mollweide map shares with the others is the need to incorporate at least a longitude grid, and in some cases also a latitude grid, if the map is to be of any use for the plotting of data. This can interfere with contours of observational parameters and produces a cluttered map surface.

The optimum charting tool for ocean-scale oceanographic data appears to be a map that combines fidelity of area with a rectangular coordinate grid. The earliest example is the Lambert projection (Fig. 8). More recently, the Peters projection, developed in 1974, (Fig. 9) has found some acceptance because its shape is very close to the standard sheet of paper accepted by printers and plotters or to the standard size of computer screens (Peters, 1989). The Peters projection is used extensively in the recent textbook Regional Oceanography: an Introduction (Tomczak and Godfrey, 1994). The display software included with the new CD-ROM of the GEBCO charts (IOC/IHO/BODC, 1994) contains the Peters projection among its standard displays.

We began this paper by pointing out the negative effect of user-friendly image processing software on the scientific standards of geographic mapping in geosciences. We should end by pointing out the tremendous advantages offered by computer image processing. To take just one example, the disadvantage of maps with curved coordinates that require redrawing for different views of the earth practically disappears if the projection is computer-generated. This makes it possible to introduce animated data displays, such as the one produced by Semtner et al. (1991) to show results from a high resolution numerical model. It uses a "photographic" view of the earth (Fig. 10) to display upper ocean temperature, but it lets the earth spin around its axis. As a result, no part of the earth's surface is disadvantaged relative to other parts at similar latitudes by suffering the gross distortions experienced at the margins. Distortions remain toward the poles, but there is no reason why a computer animation has to use the same axis of rotation as the earth itself. If fair treatment of the polar regions is required, rotation around an axis in the equatorial plane is a possibility.

It seems to us that marine scientists should approach the question of how to display data fields over large parts of the world ocean scientifically and make educated choices of projections. They should not, for the matter of convenience, be led astray by "user-friendly" software and replace a scientific approach by a display that does not con-

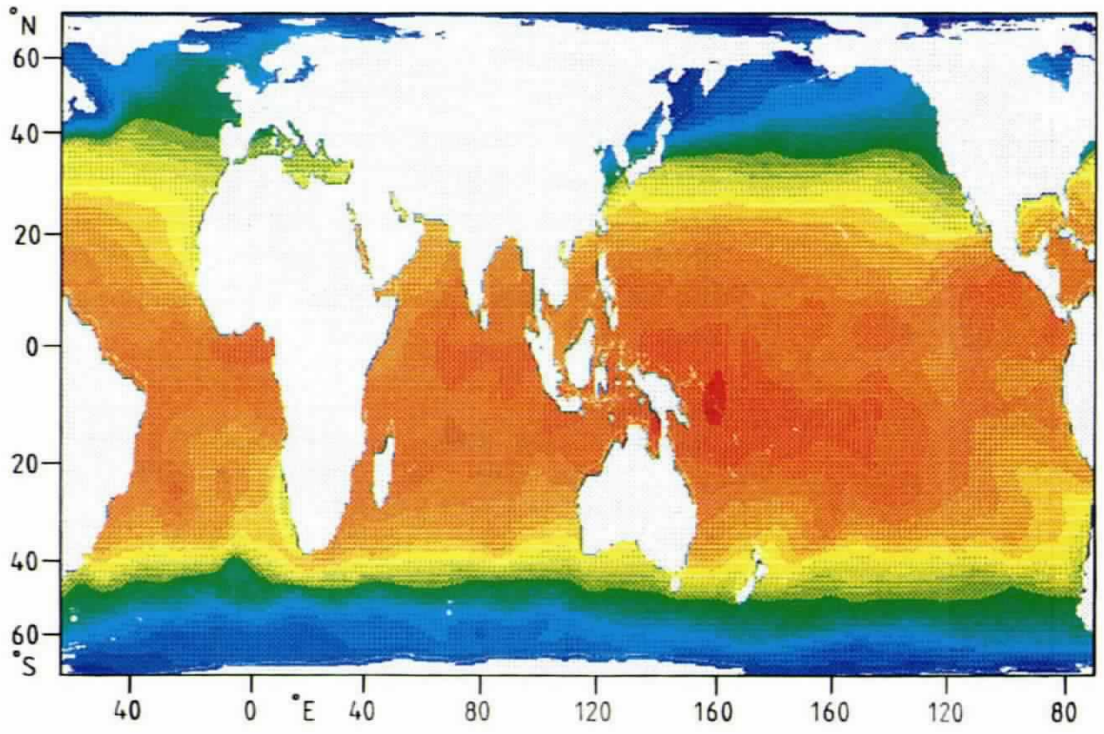

Fig. 9: The information of Figure 2 shown in Peters projection and using the same color coding. Note that the ocean appears warmer than in Figure 2. While the information built into Figures 2 and 9 is the same, the information we extract depends, among other factors, on the projection used.

serve any map property whatsoever. Producers of software should be encouraged to include a selection of the most important projections as standard display options.

If the region displayed is small, projection does, of course, not matter. The square-gridded earth will then remain the quickest and simplest way to show data. Displays of oceanic size should be based on projections appropriate for their purpose. The Peters projection will often be the best choice.

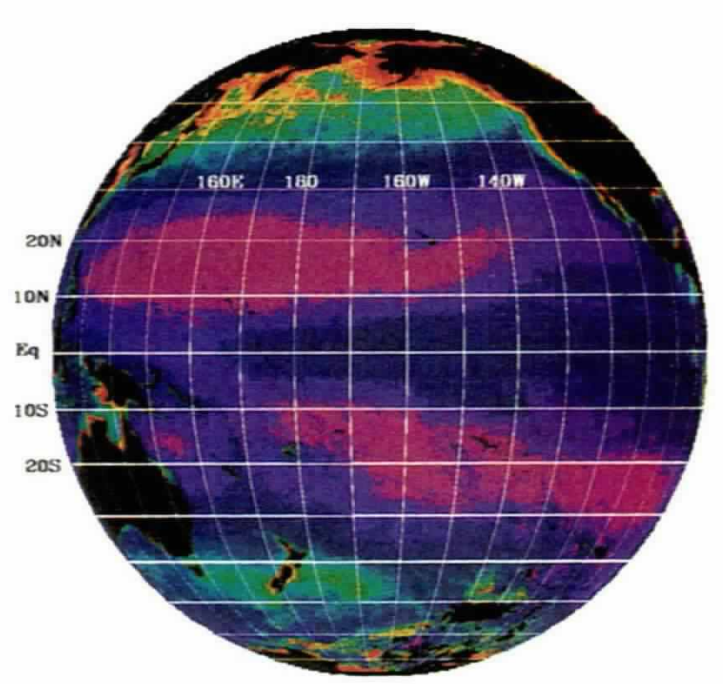

Fig. 10: A computer-generated "photographic view" of the earth, showing plankton concentration as derived from $7.5 y$ of CZCS data. The scale uses the rainbow colors with red signifying high concentrations. From Feldman et al. (1992). 


\section{Acknowledgments}

This paper was developed during a visit by $G$. Krause to the Flinders Institute for Atmospheric and Marine Sciences. Financial support from the Australian Research Council for the visit is gratefully acknowledged. We thank Colin Andrew for adding the Peters projection module to the NCAR Graphics software and producing Figures 2 and 9.

\section{References}

Feldman. G.. J.W. Mlurray and M. Leinen, 1992: Lise of the Coastal Zone Colour Scanner for EqPac planning. Oceanegraphy: 5, 143-145.

IOC/IHO/BODC. 1994: The GEBCO Digital Atlas. CD-ROM with accompanying software and supporting volume.
British Oceanographic Data Centre. Proudman Oceanographic Laboratory. Bidston Obsers atory. Birkenhead. Merseyside.

Levitus, S.. 1982: Climatolugical Alas of the Wirld Octan. NOAA Professional Paper 13.

Peters. A. 1983: The Ne' Cartugraphy. Friendship Press. New rork. $163 \mathrm{pp}$.

1989: Pe'ters Allas of the Wirtd. Longman Press. Harlow. $231 \mathrm{pp}+$ maps.

Semtner. A.J.. Jr. M.P. MeCann. S.P. Lamont. R.M. Chervin. T. Bettge and D. Middleton-Link. 1941: Animatiems From a Glohal Ocean Climate Model. L'npublished video tape.

Sharp. G.D. and R. McLain. 1993: Fisheries. El Niño-Southern Oscillation and upper-ocean temperature records: an eastern Pacific example. Oceamography. 6. 13-22

Tomczat. M. and J.S. Godfres, 1944: Regional Ocetamegraphy: An Introduction. Pergamon Press. Oxford. +22 pp. 